The article draws attention to the significant number of terms denoting the concept of the transnational literature. Their terminological delimitation or assimilation is carried out. Based on the study of lexicographic materials and modern linguistic, cultural and literary works, numerous terminology is analyzed: the intercultural literature, the Shamisso literature, the migrant literature, the guest workers' literature, the minority literature, the foreigners' literature, the immigrants' literature, the migration literature, the lost literature, etc. The first works by the transnational authors were devoted to overcoming conflicts caused by prejudice against guest workers. This issue has been replaced by the search for oneself and one's place in the new transcultural space, the search for a third space for new hybrid transnational identities in the zone of blurring and interference. In other words, crossing the borders of different cultures creates a new transnational culture of memory, in which divergent interpretations collide, events are re-evaluated, and narratives, that are passed down from generation to generation, are transformed. However, it is pointed out that there is a further evolution of the transnational literature as an intercategorical concept. The stated ideas, observations, and conclusions are only searches in the study of complex and multifaceted literary issues.

Key words: transnational literature, transmigrant, transnational culture of memory.

DOI: https://doi.org/10.32782/2410-0927-2020-12-8

УДК 811.133 .1 '373.46:53

Оксана Галян

\title{
МЕТОДОЛОГІЯ НАУКОВИХ ДОСЛІДЖЕНЬ ФІЗИЧНОЇ ТЕРМІНОСИСТЕМИ ФРАНЦУЗЬКОЇ МОВИ
}

У роботі розглянуто послідовність проведення наукової розвідки щодо аналізу теоретичної та емпіричної інформації для пізнання спеціальних понять у фізичній терміносистемі. Виділено два рівні методологічного аналізу: загальнонауковий, пов'язаний із аналізом методів, принципів, форм знань із різних наукових галузей у відповідності до об'єкта і предмета дослідження та конкретно-науковий, зумовлений обгрунтуванням принципів, норм та методів в конкретній науковій діяльності.

Для характеристики елементів фізичної терміносистеми необхідно застосувати описовий та структурний методи, а також систематизацію отриманої інформації. Встановлено, що аналіз складних фізичних термінів необхідно здійснювати поєднанням компонентного аналізу та зіставного методу. Це дозволить виділити терміноелементи і зіставити їх значення з лексемами, які мають спільну семантику. За допомогою семного аналізу встановлено семантичну структуру термінологічних одиниць, виділено смислові елементи (семи) та прокласифіковано за родовою/видовою ознаками. Метод моделювання використано для аналізу багатокомпонентних терміносполук, а з допомогою індуктивного аналізу виділено родові та видові наукові поняття.

Смисл наукового фізичного поняття розкрито за допомогою дефініцій, але поле його поширення визначено ознаками, відповідно до яких відбувається класифікація термінів. Унаслідок класифікаційного поділу угворено підкласи із предметів, явищ, процесів, властивостей і т. ін., що охоплює загальне наукове поняття.

Для дослідження термінів-словосполучень у терміносистемах проведено морфологічний аналіз їхніх компонентів та встановлено взаємозв'язок між ними. Порівняння таких даних із дослідженнями інших терміносистем та словосполучень із загальновживаною лексикою дозволило спрогнозувати ймовірні тенденції розвитку сучасної терміносистеми французької мови.

Методика дослідження скорочених словоформ полягає у виявленні закономірностей, принципів утворення абревіатур та функціонування у фаховому тексті. Встановлення повної вихідної форми лексичних словоформ $\epsilon$ недостатнім для розуміння смислу абревіатури, оскільки значення останньої в конкретному контексті може дещо змінюватись.

Ключові слова: метод дослідження, фізичний термін, семантика, наукове поняття, лексико-семантичні відношення.

Вступ. Створення та побудова наукової терміносистеми, формування методологічних основ та впорядкування термінів - це основні завдання сучасної французької лінгвістики. Методологію дослідження терміносистеми викладено в працях вітчизняних та зарубіжних мовознавців, а саме: Г. О. Винокура [17], Б. М. Головіна [7], В. П. Даниленко [8], Т. Р. Кияка [9], М. П. Кочергана [10]. В. М. Лейчика [11], Д. С. Лотте [12; 13], А. В. Суперанської [15]. Важливість правильного вибору методів і засобів дослідження пов'язана з тим, що (незалежно від того,чи термін уводиться для представлення нового поняття, чи з метою заміни наявного) потрібно здійснити аналіз та наукове обгрунтування необхідності функціонування нової лексичної одиниці в цілісній мовній системі.

(C) Галян О., 2020 
У сучасних наукових дослідженнях значно зросла роль методології для пізнання спеціальних понять. У цьому аспекті необхідно виділити два рівні методологічного аналізу: загальнонауковий (проаналізувати методи, принципи, форми знань із різних наукових галузей відповідно до об'єкта і предмета дослідження) та конкретно-науковий (пов'язаний із обгрунтуванням принципів, норм та методів в конкретній науковій діяльності). До загальнонаукових методів дослідження відносять дедукцію, індукиію, аналогію, узагальнення, систематизацію, аналіз, синтез, абстрагування, моделювання та ін. Їх використовують на теоретичному та емпіричному рівнях наукового пізнання. Окремо необхідно виділити методи, які застосовують лише на емпіричному рівні: вимірювання, спостереження, візуалізація, експериментта ін. [16].

Мета і завдання статті. Мета роботи полягає в аналізі методів дослідження фізичних термінів на основі формування однозначного наукового поняття та встановлення лексикосемантичних відношень фізичної терміносистеми. Необхідно також дослідити й особливості функціонування термінів у наукових текстах з фізики.

Результати та дискусії. На першому етапі дослідження фізичної терміносистеми (ФТ) необхідно ознайомитися з науковими поняттями з фізики та здійснити їх опис. Описовий метод слід застосовувати для аналізу становлення наукової французької лексики та опису термінологічних одиниць. Для характеристики словотворення фізичних термінів важливо використовувати структурний метод і систематизацію. Дослідження семантики фізичних термінів проводять 3 допомогою компонентного аналізу, сумісність якого полягає в розщепленні значень термінологічної одиниці і виділенні домінантних сем. Аналіз складних фізичних термінів необхідно здійснювати поєднанням компонентного аналізу та зіставного методу. Це дозволить виділити терміноелементи і зіставити їх значення з лексемами, які мають спільну семантику. Крім того, методом зіставлення французької, англійської та класичних мов у поєднанні з порівняльно-історичним методом аналізу можна провести класифікацію запозичень у хронологічному аспекті. За допомогою семного аналізу окреслюють семантичну структуру термінологічних одиниць, виділяють смислові елементи (семи) та класифікують за родовою/видовою ознаками. Метод спостереження та порівняння під час аналізу словосполук дозволить установити процеси компресії, які виявлені у дослідженні багатокомпонентних термінів із фахових словників 80-х років минулого століття у зіставленні з терміносполуками, які наявні в словниках, виданих у XXI столітті. Метод моделювання потрібно використовувати для аналізу багатокомпонентних терміносполук, з допомогою індуктивного аналізу виділяють родові та видові наукові поняття. На всіх етапах дослідження необхідно застосовувати метод словникових дефініцій, який дасть змогу узагальнити значення термінів, виявити відмінності семантичних рис і отримати повний лексикографічний опис семантичних компонентів.

Фаховим терміносистемам притаманні семантико-лексичні та структурні особливості, тому послідовний вибір методів їх дослідження - це важливий чинник у розкритті рис, ознак та зв'язків між елементами терміносистеми. Зазначимо, що кожний фізичний термін представляє наукове поняття. Тому перед тим, як упорядкувати систему термінів, передусім необхідно впорядкувати відповідну їй систему понять. Вибираючи ознаки поняття 3 термінологічного поля, потрібно дати чітке означення самого поняття і лише після цього вибрати або створити сам термін. Зрозуміти наукове поняття - означає усвідомити на логіко-поняттєвому рівні смисл та основні ознаки, що відрізняють його від інших. Для прикладу: dynamique 'динаміка' в термінологічному полі фізики означає розділ класичної механіки, яка визначає рух тіл під дією сил, що спричинили цей рух. У загальновживаному контексті це слово, вживане в значенні 'динамічний, енергійний, підприємливий' або використовуване поряд із видовим поняттям (dynamique du développement social 'динаміка соціального розвитку'), що відповідає на питання: динаміка чого? Отже, лише після формування однозначного уявлення про поняття, яке термін обслуговує, і після розуміння того, яке місце в системі понять воно займає, можна вибирати для нього відповідну лексичну одиницю [12, с. 11].

На точність означень термінів впливає класифікація понять. Зазначимо, що найдосконаліше означення неточне, оскільки воно не виявляє всіх наявних зв’язків у межах 
системи понять. Тому робота над створенням чи вдосконаленням системи термінів повинна вестися за певною методикою і у відповідній послідовності [12, с. 12]:

- аналіз структури цієї науки чи галузі техніки;

- відбір понять та їх систематизація і групування;

- визначення понять;

- побудова класифікації понять;

- відбір термінів із числа синонімів і побудова нових термінів.

Смисл наукового поняття розкривають 3 допомогою визначення, але поле його поширення визначають ознаки, за яким відбувається класифікація термінів. Поділ понять на множини проводять на логічній основі за допомогою найважливіших рис, які відділяють однакові об’єкти одного класу від об'єктів інших класів. Унаслідок класифікаційного поділу утворено підкласи із предметів, явищ, процесів, властивостей і т. ін., яких охоплює загальне наукове поняття, подібно як родове поняття об'єднує видові. Наприклад, для класифікації механічного руху в основу поділу покладено форму траєкторії (рис. 1).

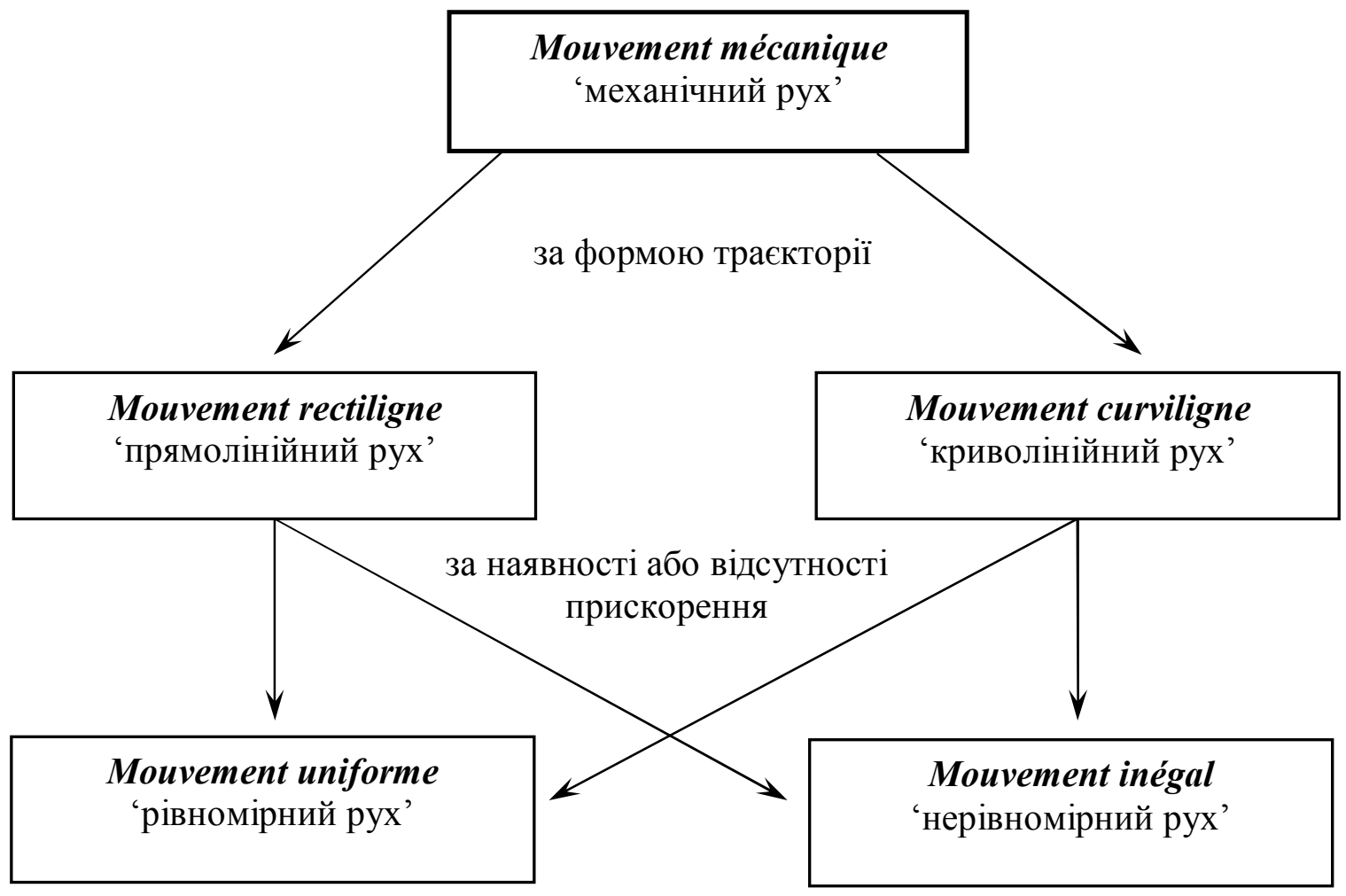

Рис. 1. Схема поділу терміна mouvement mécanique за класифікаційною ознакою

Крім того утворені класи внаслідок поділу можуть теж формувати підкласи за іншою класифікаційною ознакою. Як бачимо з рис. 1, прямолінійний і криволінійний рухи поділяють на рівномірний і нерівномірний за ознакою наявності або відсутності прискорення. Отже, впорядкування та систематизацію понять потрібно проводити відповідно до структурного поділу, який існує в досліджуваній галузі знань.

Від головного поняття physique 'фізика', відбувається поділ на відповідні напрямки, розділи, підрозділи і т. ін., у яких «ємкість» основного поняття розділено на частинні об’єми. Структурною основою науки «Фізика» $є$ поділ на окремі розділи, які досліджуємо в певній логічній послідовності: «Mécanique» 'Механіка', «Physique moléculaire et Thermodynamique» 'Молекулярна фізика і термодинаміка', «Électrodynamique» 'Електродинаміка', «Optique» 'Оптика', «Physique atomique» 'Атомна фізика', «Physique du noyau et des particules élémentaires» 'Фізика ядра і елементарних частинок'.

Ефективність упорядкування фахових слів особливо залежить від рівня розвитку тієї науки, для якої формується відповідна терміносистема. Інтенсивний розвиток фізики як науки у 
XX - XXI столітті створює передумови для такого ж швидкого розвитку ФТ. Аналіз необхідно здійснювати стосовно фізичних термінів-неологізмів, оскільки сучасна фізика $\epsilon$ «генератором» розвитку суміжних природничих та технічних наук: мікробіології, генетики, квантової хімії, мікроелектронного приладобудування, сенсорної техніки і т. ін. Отже, аналіз фізики передбачає оволодіння змістом наукових понять, що відносяться до галузі не лише класичної фізики, але й понять на стику суміжних наук, які теж номінує фізична термінологія.

3 опертям на наукові фізичні поняття з відповідними зв'язками необхідно визначити способи утворення термінів і властиві їм словотвірні елементи. Один із найпоширеніших способів утворення лексичних одиниць у французькій мові - афіксальне словотворення. У похідних словах вихідну основу доповнює один чи декілька словотвірних елементів - суфікс та префікс. Такий же спосіб словотворення продуктивний для утворення термінів, зокрема фізичних [2; 3]. У цьому випадку нове слово зберігає семантичні ознаки вихідного (lumière 'світло' - lumineux 'той, що світиться, світлий') або позначає поняття, семантика якого набуває нових ознак (galvanisme 'теорія про гальванічні струми' - galvanique 'гальванічний (елемент)'.

У термінотворенні важливо, щоб морфеми, які беруть участь у формуванні терміна для вираження понять однієї термінологічної категорії, не використовували для утворення термінів, що позначають поняття іншої термінологічної категорії [12, с. 39]. Наприклад, для вираження фізичних властивостей речовини у французькій мові використовують суфікс -ité (plasticité 'пластичність', limpidité 'прозорість'), для позначення процесу: -ation, -isation (synchronisation 'синхронізація', magnétisation 'намагнічування', dépassivation 'депасивація, активація'), а для позначення фізичного параметру - -ance (impédance 'імпеданс, повний опір', contenance 'ємкість', brilliance 'яскравість').

У термінологічних системах утворення нових слів може відбуватися складанням елементів декількох лексичних одиниць [4]. Такі новоутворення вважають складними термінами, оскільки в них можуть входити терміноелементи або частини основ від кількох термінологічних одиниць. Важливо, що об'єднання частин термінів в одне слово відбувається лише тоді, коли семантика утвореного слова єдина, але характеризовано декількома смисловими рисами. Приклади таких лексичних одиниць трапляються як у групі романських та германських мов, так і в слов'янських мовах. Аналізують такі терміни методом членування: виділяють складові, встановлюють лексеми, які їм відповідають, а також зіставляють семантику вихідних слів 3 отриманим складним терміном. Утворення таких термінів характерне не тільки для фізичної, але й для різних підсистем технічної термінології. Компоненти складних слів, основи і слова, які відносять до іменників, прикметників, дієслів, греко-латинські основи об'єднані безпосередньо або через сполучні голосні [o] та [i][14, с. 84]. Наприклад: fatiguemètre 'прилад для вимірювання втомлюваності металу', galvanoplastie 'гальванопластика', gazéiforme 'газоподібний', oléopneumatique 'масляно-пневматичний'.

Зауважимо, що деякі терміноелементи 3 розвитком відповідної галузі знань можуть виходити з ужитку. Їхня семантика настільки трансформована, що може позначати нове наукове поняття. Прикладом може слугувати елемент грецького походження -graphe, який входить як терміноелемент у складний термін. Наприклад, у другій половині ХХстоліття терміни, які визначали назви приладів і відповідні їм значення (anémographe 'анемограф самописець', barographe 'барограф самописець', thermographie 'самописний термометр'), ілюстрували, що фіксування результатів вимірювання проводиться з допомогою самописця. У зв'язку із заміною цих електромеханічних приладів відповідними сенсорами та електронними засобами передачі інформації семантика цих слів значно змінилась: anémographe 'реєструючий анемограф', barographe 'реєструючий барограф', thermographie 'термографія, реєструючий термосенсор'. У розглянутих випадках видозміни значення терміна стосуються лише частини слова, інша частина перебуває в безпосередньому зв'язку із первинним смислом слова.

Один із найпоширеніших синтаксичних способів поповнення фахової лексики сучасними термінами - це утворення словосполучень. У фізичній терміносистемі методику класифікації термінів-словосполучень логічно провести за джерелом їх походження у термінологічних системах:

1. Система термінів із досліджуваної галузі знань. 
2. Загальнотехнічні терміни.

3. Терміни суміжних дисциплін.

4. Терміни, які не відносять до споріднених дисциплін.

5. Загальновживані слова.

Слова, що походять 3 перших трьох джерел, зберігають основний набір семантичних рис, які вони отримали в момент побудови терміна-словосполучення. Слова, які постали останніми двома шляхами, можуть змінювати своє лексичне значення. Для дослідження термінівсловосполучень у терміносистемах необхідно провести морфологічний аналіз їхніх компонентів та взаємозв'язок між ними. Порівняння таких даних із дослідженнями інших терміносистем та словосполучень із загальновживаною лексикою дозволить прогнозувати ймовірні тенденції розвитку сучасної терміносистеми у французькій мові.

У фахових текстах французької мови часто натрапляємо на скорочені словоформи та абревіатури [5; 6], які можуть викликати деякі труднощі їх розуміння та перекладу. В.В. Борисов зауважує, що у випадку досконалого знання предмета, якому присвячено певний текст, а також коли читачу заздалегідь відоме значення скорочень у тексті можна досягти розуміння скорочених лексичних одиниць $[1$, с. 278]. Методика дослідження полягає у виявленні закономірностей, принципів утворення абревіатур та функціонування у фаховому тексті. Зауважимо, що встановлення повної вихідної форми лексичних словоформ є недостатнім для розуміння смислу абревіатури, оскільки значення останньої в конкретному контексті може дещо змінюватись. Отже, методологія дослідження скорочених лексичних словоформ полягає як в аналізі їхньої структури, так і самого контексту. Крім того корисно використовувати словники скорочень із французької та інших мовних систем, а також застосовувати аналогії.

Висновки. Отже, в процесі дослідження необхідно використовувати діалектичний метод із прийомами аналізу, синтезу, порівняння, узагальнення та створення поняттєвих моделей. Описово-аналітичнийє основним лінгвістичним методом, який дозволяє виявити особливості формування ФТ в рамках загальної теорії мовознавства. Крім того цей метод виявляєвплив різного роду чинників на структуру та динаміку зміни термінів, зокрема і на розвиток всієї фізичної термінології. $\mathrm{y}$ комплексі 3 діалектичними та лінгвістичними потрібно використовувати методи кількісного компонентного дослідження. Семантичну структуру термінів виділяють за допомогою семного аналізу. За лексикографічного опису та встановлення спільних і відмінних семантичних рис термінів застосовують метод словникових дефініиій.

\section{References}

1. Borisov, Volodymyr. 1972. Abbreviatsiya $i$ akronimiya. Voennyie $i$ nauchno-tehnicheskie sokrascheniya $v$ inostrannyih yazyikah. Moskva:Voenizdat.

2. Halyan, Oksana. 2012."Osnovni sufiksalni protsesy u slovotvorenni fizychnykh terminiv frantsuzkoi movy”.Visnyk Lvivskoho universytetu. Ser.: Inozemni movy 19: 148-156.

3. Halyan, Oksana. 2012. "Linhvoprahmatyka prefiksalnoi deryvatsii fizychnykh terminiv u frantsuzkii movi". Studia Germanica et Romanica: Inozemni movy. Zarubizhna literatura. Metodyka vykladannia 9(2): 64-72.

4. Halyan, Oksana. 2013 "Zakonomirnosti strukturno hramatychnoi ta semantychnoi orhanizatsii slovoskladannia fizychnykh terminiv u frantsuzkii movi”. Inozemna filolohiia 125: 36-43.

5. Halyan, Oksana. 2020 "Utvorennia ta funktsionuvannia initsialnykh skorochen u fizychniy terminosystemi (na materiali frantsuzkoi movy)". Problemy semantyky, prahmatyky ta kohnityvnoi linhvistyky 37: 13-26.

6. Halyan, Oksana. 2013 "Formuvannia i funktsionuvannia hrafichnykh ta initsialnykh abreviatur u fizychnykh tekstakh (na materiali frantsuzkoi movy)".Strukturno-semantychni $i$ kohnityvno-dyskursyvni paradyhmy suchasnoho romanskoho movoznavstva 43-46.

7. Golovin, Boris. 1987. Lingvisticheskie osnovy i ucheniya o terminah: uchebnoe posobie dlya filol. spets. vuzov. Moskva:Vysshaya shkola.

8. Danilenko, Valeriy. 1977. Russkaya terminologiya: opyt lingvisticheskogo opisaniya. Moskva: Nauka.

9. Kiyak, Taras. 1989. Lingvisticheskie osnovy i terminovedeniya: Opyt lingvisticheskogo opisaniya. Kyiv: UMKVO.

10. Kocherhan, Mykhailo. 2006. Osnovy zistavnoho movoznavstva. Kyiv: Vydavnychyi tsentr «Akademiia».

11. Leychik, Vladimir. 2009. Terminovedenie: predmety $i$, metody $i$, struktura. Moskva: Knizhn. dom «Librokom».

12. Lotte, Dmitriy. 1979. Kratkoe metodicheskoe posobie po razrabotke i uporyadocheniyu nauchno-tehnicheskoi terminologii. Moskva: Nauka. 
13. Lotte, Dmitriy. 1961. Osnovy i postroeniya nauchno-tehnicheskoy terminologii. Voprosy i teorii $i$ metodiki. Moskva: Izdatelstvo Akademii nauk SSSR.

14. Sobarshov, Ivan. 1978. Posobie po slovoobrazovaniyu frantsuzskogo yazyka dlya tehnicheskih vuzov. Moskva: Vysshaya shkola.

15. Superanskaya, Aleksandra. 1989. Obschaya terminologiya: Voprosy i terminologii. Moskva: Nauka.

16. Shternemann, R. 1989. Vvedenie v kontrastivnuyu lingvistiku. Moskva: Progress.

17. Vinokur, Grigoriy. O nekotorykh yavleniyakh slovoobrazovaniya v russkoi tehnicheskoi terminologii. Moskva: Filol.

Галян Оксана. Методология научных исследований физической терминосистемы французского языка. В работе исследована последовательность проведения научного исследования в аспекте анализа теоретической и эмпирической информации для познания специальных понятий в физической терминосистеме. Выделены два уровня методологического анализа: общенаучный, связанный с анализом методов, принципов, форм знаний из разных научных областей в соответствии с объектом и предметом исследования, и конкретно-научный обусловлен обоснованием принципов, норм и методов в конкретной научной деятельности.

Для характеристики элементов физической терминосистемы необходимо применить описательный и структурный методы, а также систематизацию полученной информации. Установлено, что анализ сложных физических терминов необходимо осуществлять сочетанием компонентного анализа и сопоставимого метода, который позволит выделить терминоэлементы и сопоставить их значения с лексемами, которые имеют общую семантику. С помощью семного анализа устанавлено семантическую структуру терминологических единиц, выделено смысловые элементы (семы) и проклассифицировано по родовому/видовому признакам. Метод моделирования использовано для анализа многокомпонентных терминосполук, а с помощью индуктивного анализа выделено родовые и видовые научные понятия.

Смысл научного физического понятия раскрыто с помощью дефиниций, но поле его распространения определено признаками, соответственно с которыми происходит классификация терминов. В результате классификационного деления образовано подклассы с предметов, явлений, процессов, свойств и т. П., которых охватывает общее научное понятие.

Для исследования терминов-словосочетаний в терминосистемах проведен морфологический анализ их компонентов и установлена взаимосвязь между ними. Сравнение этих данных с исследованиями других терминосистем и словосочетаний с общеупотребительной лексикой позволило спрогнозировать вероятные тенденции развития современной терминосистемы во французском языке.

Методика исследования сокращенных словоформ заключается в выявлении закономерностей, принципов образования аббревиатур и функционирования в профессиональном тексте. Установление полной исходной формы лексических словоформ недостаточно для понимания смысла аббревиатуры, поскольку значение последней в конкретном контексте может несколько меняться.

Ключевые слова: метод исследования, физический термин, семантика, научное понятие, лексикосемантические отношения.

Halyan Oksana. Methodology of Scientific Research in the Physical Terminological System of the French Language. This paper considers the sequence of scientific research in the context of analysis of theoretical and empirical information for learning the special concepts in the physical terminological system. There are two levels of methodological analysis: a general scientific analysis is related to the analysis of methods, principles, knowledge forms from different scientific fields in accordance with the object and subject of research and a specific scientific analysis is stipulated by substantiation of principles, norms and methods in the specific scientific activities.

To characterize the elements of physical terminology, it is necessary to apply descriptive and structural methods, as well as systematization of the obtained information. The analysis of complex physical terms shall be performed through combination of component analysis and comparative method, which allows to allocate the term elements and compare their meanings with lexical units, which have common semantics. The component analysis helps to establish semantic structure of terminological units, to allocate semantic elements (semes), and to classify by generic/aspective characteristics. The modeling method shall be used for analysis of multicomponent terminological combinations, and the inductive analysis shall help to allocate generic and aspective scientific concepts.

The meaning of the scientific physical concept shall be revealed through definition, but its distribution field shall be determined by certain features, which allow to classify the terms. The classification division forms subclasses from subjects, phenomena, processes, properties, etc., which are covered by the general scientific concept.

To study phrase terms in terminological systems, it is necessary to conduct a morphological analysis of their components and relationship between them. Comparing such data with studies of other terminological systems and phrases and with commonly used vocabulary allows to forecast the probable trends in development of modern terminology in the French language.

The research method of abbreviated word forms consists in revealing regularities, principles of formation of abbreviations and functioning in the professional text. Establishing the full initial form of lexical word forms is insufficient to understand the meaning of abbreviation, as the meaning of the latter in a particular context may slightly vary.

Key words:research method, physics term, semantics, scientific concept, lexical-semantic relations. 